\title{
Philosophiques
}

\section{Michel Morin, L'Amérique du Nord et la culture, Collection Brèches, Montréal, Hurtubise HMH,1982, 350 p.}

\section{Marc-Fernand Archambault}

Volume 12, numéro 1, printemps 1985

URI : https://id.erudit.org/iderudit/203281ar

DOI : https://doi.org/10.7202/203281ar

Aller au sommaire du numéro

Éditeur(s)

Société de philosophie du Québec

ISSN

0316-2923 (imprimé)

1492-1391 (numérique)

Découvrir la revue

Citer cet article

Archambault, M.-F. (1985). Michel Morin, L'Amérique du Nord et la culture, Collection Brèches, Montréal, Hurtubise HMH,1982, 350 p. Philosophiques,

12(1), 211-215. https://doi.org/10.7202/203281ar d'utilisation que vous pouvez consulter en ligne.

https://apropos.erudit.org/fr/usagers/politique-dutilisation/ 


\section{ÉTUDE CRITIQUE}

MICHEL MORIN, L'Amérique du Nord et la culture, Collection Brèches, Montréal, Hurtubise $\mathrm{HMH}, 1982,350$ p.

par Marc-Fernand Archambault

D'entrée de jeu, il faut bien le dire, L'Amérique du Nord et la culture de Michel Morin n'appartient pas à cette catégorie d'ouvrages que l'on se plaît à qualifier d'intéressants, intéressants comme le sont de plus en plus d'ailleurs, les travaux des philosophes universitaires au Québec. On se surprend désormais à faire des découvertes en librairie, à s'émerveiller de la diversité des intérêts et des champs parcouru par la recherche philosophique, ce qui n'était pas encore le cas il $\mathrm{y}$ a une dizaine d'années, au moment où Michel Morin, ainsi que quelques autres amorçaient une réflexion dont les résultats commencent à se faire jour.

Un livre bien singulier. Tout d'abord parce qu'il entend s'imposer comme une œuvre. Il y a là une volonté, une décision dont on ne trouve que fort peu d'exemples dans la production philosophique au Québec. Ce n'est pas une chose si facile que de faire taire les instances parlantes et de prendre à bras le corps l'ensemble du corpus philosophique, pour se lancer ainsi à l'aventure. Une entreprise certes fort périlleuse pour n'importe qui, n'importe où, mais qui semble l'être ici davantage qu'ailleurs, tellement il est difficile de prétendre à une certaine souveraineté de la pensée. Le risque est plus grand de sombrer dans une sorte de délire, dont plusieurs exemples suffisent pour le moment à notre édification, plus ou moins mégalomane ou maniaque. N'empêche que le désir ou l'exigence de l'œuvre que rien ne demande, que rien ne rend nécessaire, se développe, et cela malgré cette longue méfiance entretenue par la fréquentation des institutions universitaires. Un rien suffirait, semble-t-il, pour tout faire glisser vers ces régions obscures et mystiques où tout se perd dans le vertige des similitudes, la fascination des coïncidences. Comment éviter que la pensée prenne la forme de fantasmes, de rêves soumis à tous les embrasements, à toutes les déflagations des images et des métaphores ? Il est sans doute heureux que cette sensibilité aussi exacerbée qu'immédiate, que ces idées tout engluées qu'elles sont dans le sensible s'éteignent le plus souvent, se figent sous le regard froid de l'exigence critique et de la rigueur langagière. C'est obliger alors les détours, les médiations patientes, les mises en scène complexes qui seules savent constituer une 
culture, une culture qui sait faire la part belle au silence sur lequel elle s'édifie, c'est-à-dire celui de tous les exclus, ces sans-noms qui n'ont jamais su faire l'Histoire : les femmes, les sauvages . . .

Un livre dont la singularité même favorise le silence oublieux. Surtout qu'il se meut dans une problématique qui laisse rêveur, ce rapport qui a priori n'inspire rien de bon entre l'État, le peuple et le territoire. Thème familier au romantisme allemand, à l'idéologie allemande depuis Rerder et qui, jusqu'à Keyserling, nous a inoculé les concepts de Nation, de Culture, d'Histoire. Surtout que cette problématique s'ancre et s'enracine dans ce terreau que sont l'identité nationale et la question nationale du Québec qui préoccupe tous les intellectuels depuis plus de vingt ans. C'est dire combien nous sommes déjà dans un espace trouble. S'ajoutent à cela des accents qui font penser aux "nouveaux philosophes " et pire encore des points de rencontre avec certains thèmes de cette nouvelle pensée libérale (au sens européen du terme). Mais la véritable ambiguïté de cette pensée ne vient pas de là et surtout ne se tient pas à ce niveau ; c'est une ambiguïté que l'on serait tenté de définir comme essentielle, une ambiguïté nécessaire pour effectuer ce parcours dans le labyrinthe des idéologies tout en ne perdant pas de vue qu'il s'agit avant tout de se ménager des sentiers discrets pour atteindre les territoires mouvants et nomades de l'imaginaire.

Malgré quelques embardées qui nous valent de très belles pages, par exemple sur la puissance de l'individu, Michel Morin s'en tient à une logique du dépassement alors qu'il invite et souhaite une logique de la dislocation. Il est encore dans l'opposition entre le théorique et la fiction ou l'imaginaire. Il hésite à décrire dans le menu détail tous les excès de cette conceptualité empruntée et préfere les généralités. Il ne sait encore que faire de cette inquiétante étrangeté qui se pointe à l'horizon de sa propre pensée, dont l'Amérique n'est qu'une figure.

Bien qu'il entende parler de ces terres réelles qui permettent de se mouvoir en toute liberté, sans bornes ni frontières, sensible au désir et aux impétuosités nouvelles, l'Amérique n'en demeure pas moins une allégorie. Elle permet de dire autre chose que ce que l'on veut dire. L'Amérique dans le discours européen inaugure une ambiguité essentielle puisque l'on exclut le féminin dans son corps même. L'étrangeté de l'Amérique vient de cette découverte d'un " irratio », d'un détour de l'ancien dans le nouveau. Elle permet à l'Europe de se comprendre dans une continuité, de s'engager dans une réflexion inusitée sur les origines, de se donner des identités et des territoires tout en dressant le tableau de tous les éclatements et de toutes les multiplicités possibles. L'Amérique est tout à la fois le lieu de l'accomplissement et celui du dépérissement de l'Europe, un lieu qu'il était nécessaire d'inventer pour pouvoir penser l'Autre dans sa radicalité absolue.

Michel Morin ne se prive pas, tout en décrivant une Amérique qui se confond avec la naissance d'un État, fondé non pas sur la violence, croit-il, mais sur le droit - voué à la reconnaissance de l'irréductible autonomie de 
l'individu, une Amérique qui ne serait que ruptures et discontinuités - de nous parler d'autre chose, d'une érotique qui fonderait une politique.

Bien qu'il ne parvienne pas à trouver le passage permettant l'accès à ce que l'on pourrait appeler une science du particulier ou des singularités, son travail est essentiel. Il est un des premiers parmi les intellectuels et philosophes au Québec qui essaie avec cette ampleur de définir son propre point de vue, qui tente de construire son propre espace théorique. Sur un ton souvent péremptoire, il s'efforce avec patience de suivre les méandres nécessaires, s'impose tous les détours et les délais pour que l'œuvre s'arrache de l'immédiateté du rêve. Tout en sachant que ce travail ne peut se situer ailleurs que dans un contexte de surproduction idéologique et, partout, dévalué, caricaturé d'une manière systématique. Car malgré l'extraordinaire développement des institutions et des appareils critiques, les intellectuels du Québec contribuent toujours - il suffit de lire les Trois essais sur l'insignifiance de Pierre Vadeboncœur pour s'en convaincre - à reproduire une représentation répétitive de la réalité. Il est aisé et très commode de confondre Michel Morin avec l'un de ces découvreurs de l'Amérique que l'on voit apparaître de plus en plus parmi les intellectuels au Québec. À la limite, on pourra en faire le pendant de Vadeboncœur pour qui l'Amérique est sans âme et sans culture. Avec Morin, il s'agit de tout autre chose. Parce que le Québec n'a jamais pu se constituer en État, contrairement aux États-Unis, ce simple fait devient, à ses yeux, un élément significatif permettant de comprendre les potentialités de l'Amérique et donne libre cours à l'élaboration d'une critique de l'idéologie européenne.

Il n'existe que fort peu de sociétés où la distinction entre la culture savante et la culture populaire se présente avec autant d'acuité qu'au Québec et où les intellectuels et le peuple n'ont pas la même appréhension du réel, ni la même conception du territoire, comme il n'existe que très peu de sociétés qui peuvent se vanter d'avoir eu autant de poètes ne vivant que dans l'espérance de l'avènement d'un État fort et puissant, qui ne peuvent concevoir la culture que comme une émanation de l'État. Il est évident alors que le refus du peuple de se donner un État est vécu comme une catastrophe, comme la mise en péril d'un héritage, la fin d'un destin qui ne pouvait qu'être collectif, comme l'éparpillement de ce que Godbout, qui n'est pas mal dans son genre, appelait le texte national. Conséquence : douloureux repliement sur soi, sur une individualité qui est le corps que l'on découvre comme si c'était l'Amérique.

À vrai dire, personne ne semble avoir compris, si l'on s'en tient à la science politique, le singulier comportement des Canadiens-français face au pouvoir. Ni les intellectuels, ni les gouvernants qui ont à subir ces aberrations. Parfois on tente d'expliquer cet état de chose par l'absence d'éducation et de maturité politique, de cette maturité qui est le fait des peuples historiques, autrement dit de ceux qui ont connu les guerres civiles ou entre États. Quelques-uns vont même jusqu'à soutenir qu'il faudrait une bonne guerre pour faire comprendre à un peuple aussi peureux, aussi obtus les 
avantages et les jouissances de la souveraineté. Comment peut-on se donner une littérature et même une philosophie nationale, s'il n'y a jamais eu de massacres, de meurtres ? Comment expliquer autrement que par la bêtise cette incapacité, unique pour une société en Amérique du Nord et du Sud, de se donner un État. Un refus obstiné de comprendre que l'État seul peut réaliser les aspirations d'une société.

Il est tout à fait possible d'interpréter les choses autrement, et c'est ce que tente Michel Morin en postulant que le point de vue singulier du peuple québécois, qui n'a jamais pu trouver d'élaboration ou de représentation culturelle, peut être générateur de vérité, de réalité. Ça crève pourtant les yeux ! Jamais le peuple canadien-français ni la société québécoise n'ont accepté les contraintes et les limitations d'un État et d'un territoire, comme ils n'ont jamais adhéré à la vision catastrophique des intellectuels et des gouvernants prédisant la fin prochaine, la disparition de la société elle-même.

Cette méfiance profonde, cette désaffection, dirait Morin, à l'endroit de l'État, d'où provient-elle ? En connaît-on l'origine ? Est-il même possible de penser cette situation sans se faire piéger par les catégories de l'Histoire, sans tous les concepts de la pensée occidentale qui nous traversent de part en part ? Dans une société où le droit pré-existait en quelque sorte à la formation de l'État, un droit coutumier et un droit utopique connu à partir d'un contexte et d'un territoire tout à fait différent et lointain, il ne pouvait être question de sombrer dans l'anarchie, sous le régime sans loi ni foi des sauvages. C'est alors que, sans raison, sans même faire d'histoires, cette méfiance trouve sa ruse en acceptant l'État sous sa forme la plus libérale, tout en lui enlevant la possibilité d'être autre chose qu'une abstraction. Du point de vue du peuple canadien-français, la Constitution canadienne est un coup de génie, un chef-d'œuvre d'inefficacité.

Il y a vraiment là matière à agacer tout idéologue qui prend l'Histoire au sérieux, c'est-à-dire qui la pense sous le monde tragique. Que dire, que raconter et qu'espérer d'une société qui s'est toujours refusée à fabriquer des héros et des martyrs ? Comment entrer dans l'Histoire, si personne ne consent à mourir pour des idées ? On a beau faire, il est impossible de regarder avec les yeux de l'Histoire les Troubles de 1837 puisque le peuple refuse de s'en souvenir, d'en faire un événement. Même les événements d'octobre 1970 prennent l'allure d'une farce bouffonne platement interrompue par un déplorable accident. Au lieu de héros, voilà que l'on se retrouve avec de pauvres individus qui se sont pris au jeu de l'Histoire.

Il faut jouer le jeu qu'impose l'Histoire sans se faire prendre, car l'Histoire ne prend conscience de sa continuité que les jours où elle fait le compte des morts. Une mort qui guette toutes les sociétés qui s'y opposent. Ce désir de ne pas être de l'Histoire ou d'en sortir est l'essence même de tous les mouvements millénaristes ou messianiques qui promettent le Salut par l'instauration d'un règne nouveau, d'un monde régénéré. Le prophétisme est l'une des principales caractéristiques des peuples acculturés et colonisés, ce qui, au dire de plusieurs, aurait été et serait l'état du Québec. Il est fort curieux 
tout de même, que l'on ne retrouve pas dans la société canadienne-française de ces mouvements prophétiques fortement ancrés dans la culture populaire et généralement révolutionnaire. Curieux, car on a toujours décrit cette-société comme étant très religieuse. Le seul cas est celui de Louis Riel. Ce fut l'événement qui marqua le plus la société canadienne-française, plus encore que les Troubles. Mais jamais la société canadienne-française n'a permis l'apparition de prophètes ou de fondateurs de religion. Les hérésies provoquées par les querelles sur la répartition n'ont rien de bien excitant pour les historiens.

Michel Morin, malgré sa vigilance critique, se laisse lui aussi abuser par les mots lorsqu'il y va de son petit couplet sur le messianisme et le repliement sur soi de la société canadienne-française. Ce ne sont là que des figures de style. Des figures qui étaient peut-être nécessaires dans le déploiement du spectacle que se donnait la société vivant à part de l'Histoire, qui ne voulait rien savoir.

Comment dominer un peuple qui pour une raison ou une autre n'a aucun sens du tragique?

Département de philosophie

Collège Maisonneuve 